Pathophysiology of Haemostasis and Thrombosis
Pathophysiol Haemost Thromb 2003;33:75-83

DOI: $10.1159 / 000073850$
Received: April 1, 2003

Accepted after revision: September 3, 2003

\title{
Coagulation and Fibrinolysis in Inflammatory Bowel Disease and in Giant Cell Arteritis
}

\author{
Anton A. Vrij ${ }^{a}$ Joop Rijken ${ }^{b}$ Jan W.J. van Wersch ${ }^{c}$ \\ Reinhold W. Stockbrügger ${ }^{a}$ \\ a Department of Gastroenterology, University Hospital, Maastricht, and Departments of ${ }^{\mathrm{b}}$ Internal Medicine and \\ 'Hematology, Atrium Medical Center, Heerlen, The Netherlands
}

\section{Key Words}

Coagulation · Fibrinolysis · Crohn's disease · Ulcerative colitis - Giant cell arteritis

\begin{abstract}
Background: In inflammatory bowel disease (IBD), gut microvascular thrombosis as well as thromboembolic complications have repeatedly been observed. We examined the long-term course of markers of coagulation and fibrinolysis in relation to clinical disease activity. Materials and Methods: In a prospective study, prothrombin fragment 1 and 2 (F1.2), thrombin-antithrombin complex (TAT), antithrombin, D-dimer, plasmin- $\alpha_{2}-$ antiplasmin complex (PAP) and plasminogen activator inhibitor-1 (PAI-1) were measured in 20 patients with Crohn's disease (CD), 18 with ulcerative colitis (UC), and 19 with giant cell arteritis during active and inactive disease, as well as in 51 controls without inflammation. Results: Levels of F1.2, TAT, D-dimer, PAP and PAI-1 were significantly higher in active versus inactive $C D$ and UC. However, even after 12 months of follow-up, in CD and UC the mean levels of F1.2, D-dimer and PAP were significantly higher than the levels of the controls. Conclusions: Levels of F1.2, D-dimer and PAP were markedly raised for a long time in clinically inactive IBD, underlining a chronic state of hypercoagulation and enhanced
\end{abstract} fibrinolysis.

Copyright $@ 2003$ S. Karger AG, Basel

\section{Introduction}

In patients with inflammatory bowel disease (IBD), clinical assessment of disease activity as well as the response to treatment may be difficult, and biochemical markers reflecting these processes would be helpful [1]. Most widely used are acute phase proteins, like C-reactive protein (CRP), synthesized in the liver as a response to mediators such as interleukin-6, probably liberated from the inflammation in the gut. In general, a close link exists between coagulation and inflammation, and fibrin degradation products are capable of inducing an inflammatory response [2]. The observation of intestinal microvascular damage in Crohn's disease (CD) [3-6] as well as fibrinoid microvascular thrombi in the gut mucosa of patients with ulcerative colitis (UC) [7] could be of etiologic importance.

Recurrent thromboembolic complications have been reported in $10-13 \%$ of patients with IBD $[8,9]$, with a 3 -fold increased risk of developing deep venous thrombosis and pulmonary embolism in an age- and sex-matched population-based study [10]. Also, inherited disorders of hypocoagulation appear to protect against IBD [11]. However, no single inherited procoagulant disorder, like e.g. factor V Leiden [12-15], was found to account for the risk of venous thrombosis in IBD [16]. Although alterations in blood markers of coagulation and fibrinolysis have been found in patients with IBD [16-26], the duration of follow-up was relatively short.

\footnotetext{
Anton A. Vrij, MD

Twenteborg Hospital, Department of Internal Medicine

Postbox 7600

NL-7600 SZ Almelo (The Netherlands)

Tel. +31 0546 693693, Fax +31 0546 693830, E-Mail a.vrij@twenteborg.nl
} 
In a prospective manner and during a longer time of follow-up than was studied previously, we investigated the course of markers for coagulation activation [prothrombin fragment 1 and 2 (F1.2), thrombin-antithrombin complex (TAT)] and coagulation inhibition (antithrombin, AT), as well as fibrinolysis activation (Ddimer) and fibrinolysis inhibition [plasmin- $\alpha_{2}$-antiplasmin complex (PAP), plasminogen activator inhibitor-1 (PAI-1)]. These protein complexes or end products with relatively long plasma half-lives were chosen to reliably characterize both coagulation and fibrinolysis processes, as well as the relationship with disease activity over a longer time span. The markers were determined in patients with IBD, as well as in patients with a well-known vasculitis (giant cell arteritis, GCA), to demarcate the specificity of our findings. GCA has characteristics of a granulomatous disease similar to $\mathrm{CD}$, although in GCA, medium to large arteries are generally involved [27]. However, GCA is well diagnosed with a temporal artery biopsy, while in patients with a small-vessel vasculitis like in HenochSchönlein purpura or (microscopic) polyangiitis, a uniform histology diagnosis is more difficult to obtain.

Our hypothesis was that in active but also in inactive IBD and GCA, levels of coagulation and fibrinolysis were raised. Furthermore, to assess the possible role of coagulation and fibrinolysis factors as markers of disease activity, a correlation with indices of clinical activity as well as biochemical activity like the erythrocyte sedimentation rate (ESR) or CRP was investigated.

\section{Materials and Methods}

\section{Patients}

In a prospective study, performed at the Department of Internal Medicine of the Atrium Medical Center Heerlen, The Netherlands, 38 newly diagnosed in- or outpatients with IBD were enrolled from December 1991 to December 1994 and followed in an active and inactive phase of disease. The Ethics Committee of the Atrium Medical Center Heerlen approved the study and patients provided written informed consent before entry. Twenty patients with CD and 18 patients with UC were included with a median duration of follow-up of 12 (range 6-21) months. In CD and UC, the diagnosis was documented according to the criteria of Lennard-Jones [28]. Although it was not an exclusion criterion in this study, no patients were categorized as having indeterminate colitis.

In $C D$, the severity of disease was classified according to the Crohn's Disease Activity Index (CDAI) [29]. Active disease was defined as a CDAI score $>150$. At entry, 6 patients had a CDAI $>450,11$ patients had a CDAI score between 300 and 450 and in 3 patients, the CDAI ranged from 150 to 299.

In patients with UC, severity of disease was classified according to the Truelove-Witts criteria [30]. For statistical purposes, the classification was quantitatively modified [31]. The score in severe disease was between 15 and 18 , in moderate disease between 9 and 14 , in mild disease between 4 and 8 and in inactive disease it was 3 or less. At entry, disease activity was severe in 12 patients, moderate in 6 patients and none had mild or inactive disease.

In 19 patients with a histologically proven and newly diagnosed GCA, activity was assessed according to the criteria of the ARA [27], as well as by the ESR and CRP levels. Since the GCA group was considerably older than the group of IBD patients, separate groups of controls were included.

Twenty-five age- and sex-matched orthopedic patients, seen before elective minor surgery, served as a control group for patients with IBD. They had no signs of vasculitis or gastrointestinal disease. Also, 26 age- and sex-matched controls, consisting of 19 healthy females of an older age and 7 male urology patients seen in the outpatient clinic because of benign prostate hypertrophy, were all without signs of inflammation and served as a control group for patients with GCA.

None of the patients was on oral anticoagulants or aspirin. Patients with preexisting liver disease, with coexisting malignancy, or who were pregnant and patients who refused consent were excluded from the study.

Depending on the severity of disease, therapy in IBD consisted of oral 5-aminosalicylic acid (5ASA) and/or prednisone (starting dose varying between 0.5 and $1 \mathrm{mg} / \mathrm{kg} /$ day $)$, azathioprine $(2.5 \mathrm{mg} /$ $\mathrm{kg}$ ), and was sometimes combined with enema therapy. Prednisone was started in case of insufficient clinical response to 5ASA treatment in active CD (CDAI >150) and moderate to severe UC (Ulcerative Colitis Activity Index, UCAI >8). In active GCA, oral prednisone (absolute dose $40 \mathrm{mg} /$ day) was started, and according to the clinical and acute phase response, dosage was gradually lowered [32]. None of the patients received plasma derivatives other than packed cells, and none of the patients with IBD had surgery during follow-up.

Plasma samples were collected during active UC, CD and GCA before conventional therapy, and - after intervals of 3 months - in inactive disease while on low-dose prednisone (less than $15 \mathrm{mg} /$ day), azathioprine and/or mesalazine (oral or enema) in the IBD group. In the noninflammatory controls, blood samples were taken twice within a month before surgery. All patients with UC underwent a sigmoidoscopy and/or colonoscopy at entry, and in CD (an additional) selective small bowel enteroclysis was performed. However, unlike the clinical activity and laboratory investigations, follow-up endoscopies were not performed in a standardized manner.

The characteristics of patients and controls are shown in table 1.

\section{Methods}

All blood samples were drawn fasting between 8 and 10 a.m. to avoid diurnal variation [33]. After a resting period of $20 \mathrm{~min}$, nontraumatic venipuncture was performed in a standardized manner by trained operators. After discarding the first $2 \mathrm{ml}$ of blood, $4.5 \mathrm{ml}$ of blood was drawn into test tubes with $0.5 \mathrm{ml}$ citrate and immediately kept on ice. Within $1 \mathrm{~h}$ from sample collection, all test tubes were centrifuged for $30 \mathrm{~min}(3,000 \mathrm{~g})$ at $4{ }^{\circ} \mathrm{C}$. Platelet poor plasma was aspirated from the central part of the plasma, without disturbing either the top layer or the buffy coat. The plasma was snap-frozen in aliquots, stored at $-70^{\circ} \mathrm{C}$ in plastic tubes and thawed in a water bath at $37^{\circ} \mathrm{C}$ for $5 \mathrm{~min}$, immediately prior to serial analysis. Plasma concentrations of F1.2, TAT, D-dimer, PAP and PAI-1 were determined by sandwich-type enzyme immunoassays, and the activity of AT was measured by a chromogenic substrate (Boehringer Mannheim). The 
Table 1. Characteristics of the patients and control groups ( $\mathrm{C} 1$ for $\mathrm{CD}$ and $\mathrm{UC}$ and $\mathrm{C} 2$ for GCA)

\begin{tabular}{llllll}
\hline & CD & UC & GCA & C1 & C2 \\
\hline Patients & 20 & 18 & 19 & 25 & 26 \\
Female & 14 & 11 & 14 & 16 & 19 \\
Male & 6 & 7 & 5 & 9 & 7 \\
Median age, years & $34(20-71)$ & $47(17-86)$ & $72(65-88)$ & $41(22-74)$ & $71(67-84)$ \\
Median follow-up, months & $12(6-21)$ & $12(6-18)$ & $10(6-22)$ & $1(0.5-1)$ & $1(0.5-1)$ \\
Smoking & 8 & 4 & 6 & 6 & 7 \\
Oral contraceptive use & 5 & 4 & 0 & 8 & 0 \\
\hline
\end{tabular}

Figures in parentheses represent range. intra-assay coefficient of variation was between 5 and $10 \%$ for the assays.

CRP was measured by an enzyme immunoassay (Behring, Germany; normal values $0-5 \mathrm{mg} / \mathrm{l}$ ), and the ESR was measured according to the Westergren method (normal values $5-15 \mathrm{~mm} / \mathrm{h}$ ).

\section{Statistical Analysis}

All patients were included in the follow-up data. In UC, CD and GCA, median values with the minimum-maximum range (table 1) or mean values with the $95 \%$ confidence intervals (CI) for the mean (table 2) were calculated in case of a skewed or even distribution of data, respectively. To test differences for significance, the MannWhitney signed-rank test was performed for the longitudinal patient follow-up as well as the Mann-Whitney $U$ test to compare the three patient groups with the age- and sex-matched control groups (table 2). Furthermore, the Spearman rank correlation coefficient and the two-tailed significance of the correlation were calculated between coagulation, fibrinolysis, and other biochemical markers and disease activity indices. A correction for multiple comparisons was performed using the Bonferroni-adjusted level of significance. Calculations were done with CD and UC as separate groups, not with IBD as a whole. For statistical analysis, SPSS 10.0 software was used (SPSS, USA).

\section{Results}

\section{Markers of Coagulation Activation and Inhibition in Active and Inactive Disease (table 2)}

F1.2 was significantly higher in active and inactive $\mathrm{CD}, \mathrm{UC}$ and GCA compared to the controls $(\mathrm{p}<0.0001)$. Also, F1.2 values were higher in active than in inactive CD or UC $(p=0.005)$ unlike in active versus inactive GCA ( $p=0.297)$. TAT was higher in active CD, UC and GCA compared to the controls $(\mathrm{p}<0.0001)$, and higher in active versus inactive CD or UC $(\mathrm{p}<0.001)$ unlike GCA $(\mathrm{p}=0.402)$. AT activity was normal in active and inactive IBD, but raised in inactive compared to active GCA ( $p<$ $0.0001)$.

Coagulation and Fibrinolysis in IBD and GCA
In the noninflammatory control groups, laboratory values were within normal limits.

\section{Markers of Fibrinolysis Activation and Inhibition in} Active and Inactive Disease (table 2)

D-dimer was significantly higher in active and inactive $\mathrm{CD}, \mathrm{UC}$ and GCA compared to the controls $(\mathrm{p}<0.0001)$, and higher in active versus inactive $\mathrm{CD}, \mathrm{UC}$ or GCA ( $\mathrm{p}<$ 0.0001). PAP was higher in active CD, UC and GCA compared to the controls $(\mathrm{p}<0.0001)$, as well as in active versus inactive $\mathrm{CD}(\mathrm{p}=0.002), \mathrm{UC}(\mathrm{p}<0.0001)$ or GCA $(\mathrm{p}<0.0001)$. PAI-1 was higher in active UC and GCA, but not in active CD compared to the controls $(p=0.003$, $\mathrm{p}=0.001, \mathrm{p}=0.582$, respectively). PAI-1 levels were reduced in inactive compared to active $\mathrm{CD}(\mathrm{p}=0.011)$, $\mathrm{UC}(\mathrm{p}<0.0001)$ and GCA $(\mathrm{p}=0.006)$.

PAP and PAI-1 values were normal in the controls, but D-dimer was higher in the elderly (GCA) controls $(\mathrm{p}=$ $0.001)$.

\section{Correlations between Coagulation and Fibrinolysis Markers}

In CD and UC, F1.2 correlated with TAT, D-dimer, PAP (all $\mathrm{p}<0.0001)$, and PAI-1 $(\mathrm{p}=0.012)$. TAT correlated with D-dimer, PAP and PAI-1 $(\mathrm{p}<0.0001)$. AT did not correlate with the other coagulation and fibrinolysis markers in CD and UC, except for TAT in UC ( $p=$ 0.009). D-dimer correlated with PAP $(p<0.0001)$ in CD and UC, as well as PAI-1 in CD ( $p=0.002)$, but not in UC. PAP correlated with PAI-1 in UC $(p=0.007)$ unlike in $\mathrm{CD}$.

In GCA, the markers F1.2 and TAT did not correlate with the other coagulation and fibrinolysis markers. Ddimer correlated with PAP and PAI- $1(\mathrm{p}<0.0001$ and $\mathrm{p}=$ $0.006)$, and PAP correlated with AT $(\mathrm{p}=0.002)$ and PAI-1 $(\mathrm{p}=0.003)$.

Pathophysiol Haemost Thromb 2003;33:75-83 
Table 2. F1.2, TAT, AT, D-dimer, PAP, PAI-1, ESR and CRP in active and inactive CD $(\mathrm{n}=20), \mathrm{UC}(\mathrm{n}=18)$ and GCA $(\mathrm{n}=19)$

\begin{tabular}{|c|c|c|c|c|c|c|c|c|}
\hline \multirow[t]{2}{*}{ Laboratory tests } & \multicolumn{2}{|l|}{$\mathrm{CD}, \mathrm{CDAI}$} & \multicolumn{2}{|l|}{ UC, UCAI } & \multicolumn{2}{|l|}{ GCA, ARA } & \multirow[t]{2}{*}{$\mathrm{C} 1$} & \multirow[t]{2}{*}{$\mathrm{C} 2$} \\
\hline & $>150$ & $<150$ & $>4$ & $<4$ & active & inactive & & \\
\hline \multicolumn{9}{|c|}{$\mathrm{F} 1.2(0.26-1.14 \mathrm{mmol} / \mathrm{l})$} \\
\hline Mean & 1.70 & 0.87 & 1.61 & 1.04 & 2.37 & 1.52 & 0.56 & 0.70 \\
\hline $95 \% \mathrm{CI}$ & $0.99-2.41$ & $0.73-1.01$ & $1.24-1.97$ & $0.74-1.34$ & $1.11-3.64$ & $1.04-1.99$ & $0.46-0.67$ & $0.56-0.84$ \\
\hline Significance & $* * *$ & $* *$ & $* * *$ & $* *$ & $* * *$ & $* * *$ & & \\
\hline \multicolumn{9}{|l|}{ TAT $(0.7-4.2 \mu \mathrm{g} / \mathrm{l})$} \\
\hline Mean & 5.55 & 2.34 & 5.35 & 2.85 & 5.08 & 3.77 & 2.34 & 2.24 \\
\hline $95 \% \mathrm{CI}$ & $3.61-7.49$ & $1.50-3.18$ & $3.93-6.77$ & $1.85-3.85$ & $3.14-7.02$ & $3.09-4.43$ & $1.94-2.75$ & $1.81-2.68$ \\
\hline Significance & $* * *$ & n.s. & $* * *$ & n.s. & $* * *$ & $* *$ & & \\
\hline \multicolumn{9}{|l|}{ AT (80-120\%) } \\
\hline Mean & 96.5 & 98.8 & 105.4 & 102.8 & 97.0 & 116.3 & 98.9 & 100.0 \\
\hline $95 \% \mathrm{CI}$ & $89.7-103.2$ & $93.6-103.9$ & $95.7-115.1$ & $99.3-106.2$ & $89.5-104.5$ & $109.9-122.6$ & $94.8-103.0$ & $95.1-105.0$ \\
\hline Significance & n.s. & n.s. & n.s. & n.s. & n.s. & $* * *$ & & \\
\hline \multicolumn{9}{|c|}{ 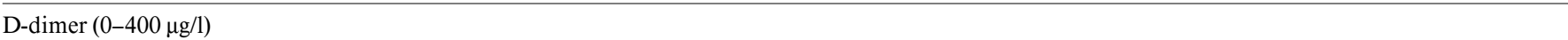 } \\
\hline Mean & 1,469 & 583 & 1,509 & 566 & 1,780 & 853 & 283 & 414 \\
\hline $95 \% \mathrm{CI}$ & $1,139-1,799$ & $373-794$ & $1,126-1,891$ & $389-744$ & $1,151-2,410$ & $188-1,518$ & $244-321$ & $352-476$ \\
\hline Significance & $* * *$ & $* * *$ & $* * *$ & $* * *$ & $* * *$ & $* * *$ & & \\
\hline \multicolumn{9}{|l|}{ PAP $(80-470 \mu \mathrm{g} / \mathrm{l})$} \\
\hline Mean & 948 & 550 & 1,059 & 540 & 1,162 & 735 & 282 & 259 \\
\hline $95 \% \mathrm{CI}$ & $745-1,151$ & $373-727$ & $844-1,274$ & $456-624$ & $1,017-1,306$ & $617-853$ & $242-322$ & $215-302$ \\
\hline Significance & $* * *$ & $* * *$ & $* * *$ & $* * *$ & $* * *$ & $* * *$ & & \\
\hline \multicolumn{9}{|c|}{ PAI-1 $(4.0-43.0 \mu \mathrm{g} / \mathrm{l})$} \\
\hline Mean & 31.0 & 16.3 & 47.6 & 16.4 & 49.2 & 25.4 & 26.8 & 30.0 \\
\hline $95 \% \mathrm{CI}$ & $21.5-40.5$ & $12.5-20.2$ & $35.7-59.5$ & $13.0-19.7$ & $37.1-61.3$ & $14.6-36.3$ & $21.9-31.7$ & $25.7-34.2$ \\
\hline Significance & n.s. & $* *$ & $* *$ & $*$ & $* *$ & $*$ & & \\
\hline \multicolumn{9}{|l|}{$\operatorname{ESR}(5-15 \mathrm{~mm} / \mathrm{h})$} \\
\hline Mean & 51 & 10 & 42 & 11 & 82 & 14 & 15 & 17 \\
\hline $95 \% \mathrm{CI}$ & $34-68$ & $6-13$ & $32-51$ & $9-13$ & $69-95$ & $11-17$ & $7-18$ & $10-20$ \\
\hline Significance & $* * *$ & $*$ & $* * *$ & n.s. & $* * *$ & n.s. & & \\
\hline \multicolumn{9}{|l|}{$\overline{\mathrm{CRP}}(0-5 \mathrm{mg} / \mathrm{l})$} \\
\hline Mean & 122 & 6 & 78 & 7 & 108 & 6 & 7 & 8 \\
\hline $95 \% \mathrm{CI}$ & $83-161$ & $5-7$ & $54-102$ & $6-9$ & $72-143$ & $5-7$ & $5-9$ & $6-10$ \\
\hline Significance & $* * *$ & n.s. & $* * *$ & n.s. & $* * *$ & n.s. & & \\
\hline
\end{tabular}

Mean and $95 \%$ CI of the mean (lower to upper bounds) are shown. The significance of the differences between the means of the separate groups of activity in IBD and GCA, and their respective group of controls (C1 for IBD, C2 for GCA) was calculated by means of the Mann-Whitney U test.

$* \mathrm{p}<0.05 ; * * \mathrm{p}<0.01 ; * * * \mathrm{p}<0.0001$. n.s. $=$ Not significant.

\section{Correlations of Coagulation and Fibrinolysis Markers with Clinical and Biochemical Indices of Disease Activity (table 3)}

In $\mathrm{CD}$, the CDAI as well as the ESR and CRP correlated with F1.2, TAT, D-dimer, and PAP, but not with AT. Also, PAI-1 correlated with the CDAI and ESR, but not with CRP. In UC, the UCAI as well as the ESR and CRP correlated with F1.2, TAT, D-dimer, PAP and PAI-1, but not AT. In GCA, the ESR did not correlate with F1.2 or TAT, but inversely correlated with AT $(\mathrm{r}=-0.428 ; \mathrm{p}=0.005)$. The ESR however correlated with D-dimer $(\mathrm{r}=0.726 ; \mathrm{p}<0.0001)$, PAP $(\mathrm{r}=0.710 ; \mathrm{p}<$ $0.0001)$, and PAI-1 levels $(r=0.425 ; p=0.005)$.

\section{Correlation of Coagulation and Fibrinolysis Markers} with the Extent of Bowel Involvement at Entry

The endoscopic extension of bowel involvement in patients with active $\mathrm{CD}$ or $\mathrm{UC}$ was investigated as well as its relationship to the coagulation and fibrinolysis markers.

Patients with CD involving only the small bowel $(\mathrm{n}=$ $10)$ or only the colon $(n=4)$, and CD of both small and large bowel segments $(n=6)$ were distinguished. Levels of F1.2, TAT and AT, as well as D-dimer, PAP and PAI-1 were not significantly different according to disease localization and extension. However, the number of patients does not allow us to make definite statements in this respect. 
Table 3. Spearman-rank correlation coefficient values and the two-tailed significance of the correlation are shown between the coagulation and fibrinolysis laboratory tests, and clinical (CDAI, UCAI) and biochemical (ESR, CRP) indices of activity in $\mathrm{CD}$ and $\mathrm{UC}$

\begin{tabular}{|c|c|c|c|c|c|c|}
\hline \multirow[t]{2}{*}{ Laboratory tests } & \multicolumn{3}{|l|}{$\mathrm{CD}$} & \multicolumn{3}{|l|}{$\mathrm{UC}$} \\
\hline & CDAI & ESR & CRP & UCAI & ESR & CRP \\
\hline F1.2 & 0.376 & 0.453 & 0.382 & 0.383 & 0.483 & 0.390 \\
\hline Significance & $* * *$ & $* * *$ & $* * *$ & $* * *$ & $* * *$ & $* * *$ \\
\hline TAT & 0.442 & 0.369 & 0.450 & 0.508 & 0.541 & 0.448 \\
\hline Significance & $* * *$ & $* * *$ & $* * *$ & $* * *$ & $* * *$ & $* * *$ \\
\hline AT & 0.051 & 0.037 & -0.042 & 0.085 & 0.244 & 0.047 \\
\hline Significance & n.s. & n.s. & n.s. & n.s. & n.s. & n.s. \\
\hline D-dimer & 0.514 & 0.502 & 0.475 & 0.433 & 0.522 & 0.462 \\
\hline Significance & $* * *$ & $* * *$ & $* * *$ & $* * *$ & $* * *$ & $* * *$ \\
\hline PAP & 0.412 & 0.265 & 0.269 & 0.502 & 0.553 & 0.449 \\
\hline Significance & $* * *$ & $* *$ & ** & $* * *$ & $* * *$ & $* * *$ \\
\hline PAI-1 & 0.265 & 0.317 & 0.213 & 0.455 & 0.465 & 0.354 \\
\hline Significance & $* *$ & $* *$ & n.s. & $* * *$ & $* * *$ & $* *$ \\
\hline ESR & 0.633 & & & 0.703 & & \\
\hline Significance & $* * *$ & & & $* * *$ & & \\
\hline CRP & 0.806 & & & 0.736 & & \\
\hline Significance & $* * *$ & & & $* * *$ & & \\
\hline
\end{tabular}

${ }^{* *} \mathrm{p}<0.015$ (Bonferroni-adjusted significance); ${ }^{* * *} \mathrm{p}<0.0001$. n.s. $=$ Not significant.
Patients with UC involving only the rectum and/or sigmoid colon $(n=9)$, and UC extended to the more proximal colon segments (left-sided colitis: $\mathrm{n}=3$; pancolitis: $\mathrm{n}=6)$ were distinguished. Levels of TAT $(\mathrm{p}=0.022)$ as well as D-dimer $(\mathrm{p}=0.031)$, PAP $(\mathrm{p}=0.002)$ and PAI-1 ( $\mathrm{p}$ $=0.049$ ) were significantly higher in more extensive UC, and a correlation with the extent of bowel involvement at entry was found with TAT $(r=0.534 ; \mathrm{p}<0.0001)$, Ddimer $(r=0.477 ; p=0.002)$, PAP $(r=0.446 ; p=0.004)$, PAI-1 $(r=0.463 ; p=0.003)$, as well as CRP $(r=0.618 ; p<$ $0.0001)$.

\section{The Course of Coagulation and Fibrinolysis Markers over Time in $C D$ and $U C$}

In $\mathrm{CD}$, after 12 months of follow-up, the mean F1.2 was higher by a factor of 1.5 than the control value $(0.86$ and $0.56 \mathrm{mmol} / 1$, respectively; $p<0.0001$ ), and in 3 of 18 patients tested it was above the upper reference value. As a contrast, TAT equalized the mean control value between $3(p=0.048)$ and 6 months $(p=0.892)$. The AT activity in $\mathrm{CD}$ was stable and not different from the controls during 12 months of follow-up (fig. 1).

The mean D-dimer level in CD was higher by a factor of 1.9 than in the controls (524 and $283 \mu \mathrm{g} / \mathrm{l} ; \mathrm{p}<0.0001$; above upper reference in 11 of 18 patients), and the mean PAP level was higher by a factor of 1.7 after 12 months (486 and $282 \mu \mathrm{g} / 1 ; \mathrm{p}<0.0001$; above upper reference in 8 of 18 patients). The initially higher mean values of PAI-1 became lower by a factor of 1.7 as compared to the controls $(16.0$ and $26.8 \mu \mathrm{g} / \mathrm{l} ; \mathrm{p}=0.005$; in 1 of 18 patients below the lower reference value) (fig. 2).

In UC, after 12 months the mean F1.2 count was higher by a factor of 1.5 than in the controls $(0.89$ and $0.56 \mathrm{mmol} / \mathrm{l}$, respectively; $\mathrm{p}=0.009$; above upper reference in 6 of 17 patients). However, TAT equalized the controls between $3(p=0.024)$ and 6 months $(p=0.225)$. As in $\mathrm{CD}$, the AT activity course in UC did not differ from the controls (fig. 3).

The mean D-dimer level was higher by a factor of 2.0 in UC than in the controls (555 and $283 \mu \mathrm{g} / \mathrm{l} ; \mathrm{p}<0.0001$; above upper reference in all 17 patients tested), and the mean PAP level was higher by a factor of 1.6 than in the controls (461 and $282 \mu \mathrm{g} / 1 ; \mathrm{p}<0.0001$; above upper reference in 11 of 17 patients) after 12 months. As in CD, initially higher mean values of PAI-1 became lower by a factor of 1.7 as compared to the controls ( 15.9 and $26.8 \mu \mathrm{g} / \mathrm{l}$; $\mathrm{p}=0.005$; no scores below the lower reference value) (fig. 4). 


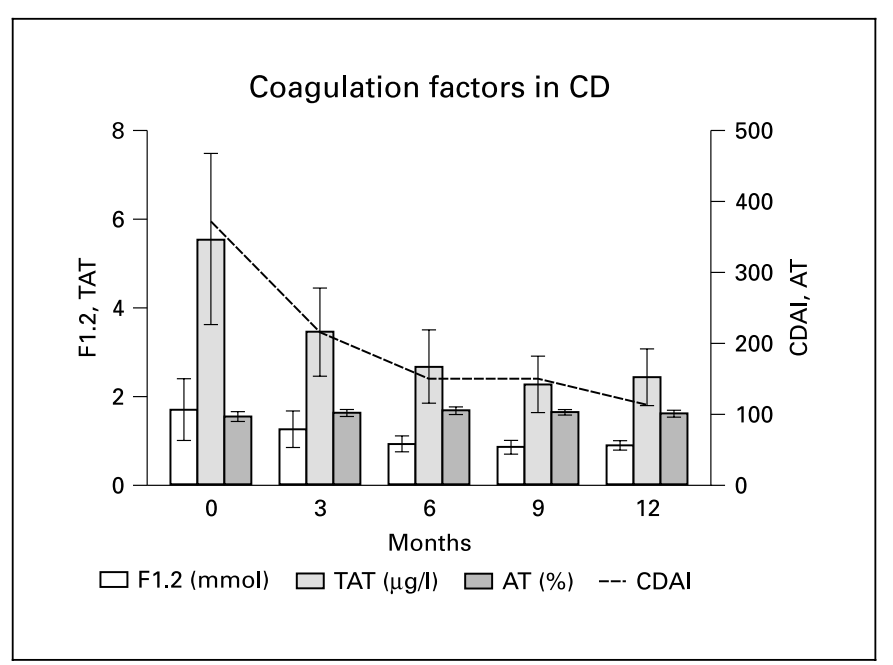

Fig. 1. Mean levels of F1.2, TAT and AT on entry and during 12 months of follow-up in 20 patients with CD. Sample sizes of F1.2, TAT and AT at 0,3,6,9 and 12 months were 20,20,18,20 and 18 . The interrupted line shows the course of the CDAI. AT levels were in the normal range during 12 months of follow-up. Within 6 months, the mean TAT level was equal to the control group. However, even after 12 months of follow-up, the mean F1.2 levels were 1.5 times higher than the levels of the control group.

\section{Discussion}

Not only in the active, but also in the inactive phase of IBD we found a significantly higher level of coagulation and fibrinolysis as compared to the age- and sex-matched controls. Second, long-term patterns of coagulation and fibrinolysis were similar in GCA and IBD. This suggests that common pathways, e.g. microvascular thrombosis or vasculitis, may play a role in both IBD and GCA. Although we did not examine coagulation activity in biopsies in the present study, we and others have shown that microthrombi are present in gut mucosa even when histology shows no inflammation [7, 34]. We therefore hypothesize that hypercoagulation and disturbed fibrinolysis might add to the chronicity of these diseases.

Unlike the study of Henegan et al. [35], but analogous to the study of van Bodegraven et al. [36], we did not find a significantly low AT level in IBD as compared to the controls. In GCA however, levels of AT were significantly lower in active versus inactive GCA. Also, TAT levels were raised both in active and inactive GCA, and this might point to a disseminated intravascular coagulation with more consumption of AT during active disease as compared to IBD [37].

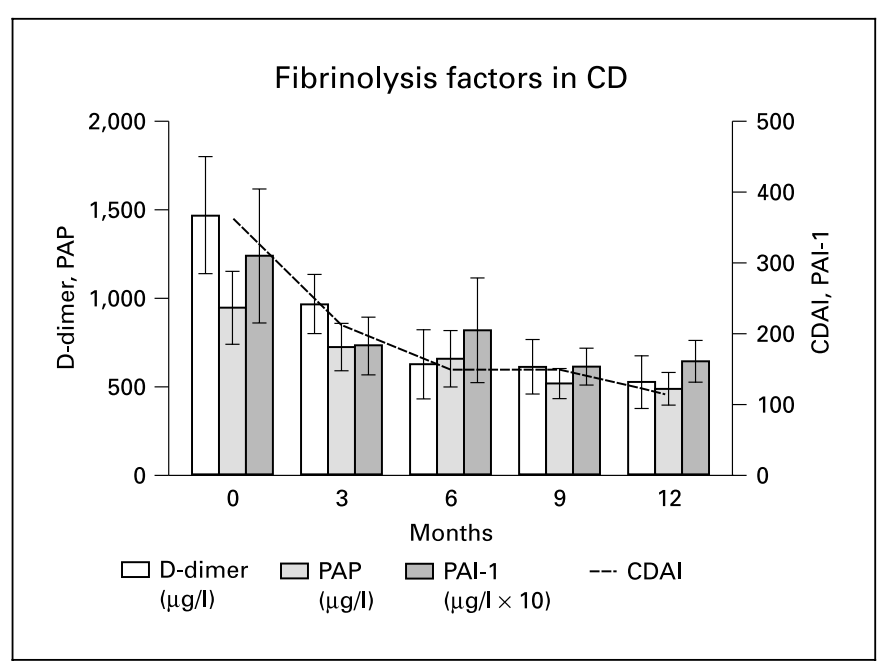

Fig. 2. Mean levels of D-dimer, PAP and PAI-1 on entry and during 12 months of follow-up in 20 patients with CD. Sample sizes of Ddimer, PAP and PAI-1 at 0, 3, 6, 9 and 12 months were 20, 20, 18, 20 and 18. The interrupted line shows the course of the CDAI. After 12 months of follow-up, the mean D-dimer and PAP levels were 1.9 and 1.7 times higher than the levels of the control group. However, PAI-1 levels were 1.7 times lower in $\mathrm{CD}$ as compared to the control group after 12 months of follow-up.

In the two noninflammatory control groups, the only difference was a higher D-dimer in the older patients, also found by others [38]. Although we cannot find a clear explanation, it might be a feature of more background atherosclerosis occurring in the elderly. However, we would have expected that the other markers would be raised to some degree as well $[39,40]$.

In this study, a clinical remission was not documented with follow-up endoscopy and histology in IBD. Therefore, it is possible that at least part of the raised hemostasis activity was due to ongoing inflammation. At entry, levels of coagulation (TAT) as well as fibrinolysis factors (D-dimer, PAP, PAI-1) were lower in proctosigmoiditis than in more extensive UC. Although this suggests a relationship between the size of the mucosal defect and the magnitude of coagulation activation, these markers also correlated with CRP, fitting in with the concept of a more generalized systemic inflammatory and hemostatic response.

After treatment, CRP levels rapidly declined but our treatment regimen with mesalazine, prednisone and azathioprine did not alter the pattern of hypercoagulation and fibrinolysis during long-term follow-up. Although patients were clinically well, our data suggest that their dis- 


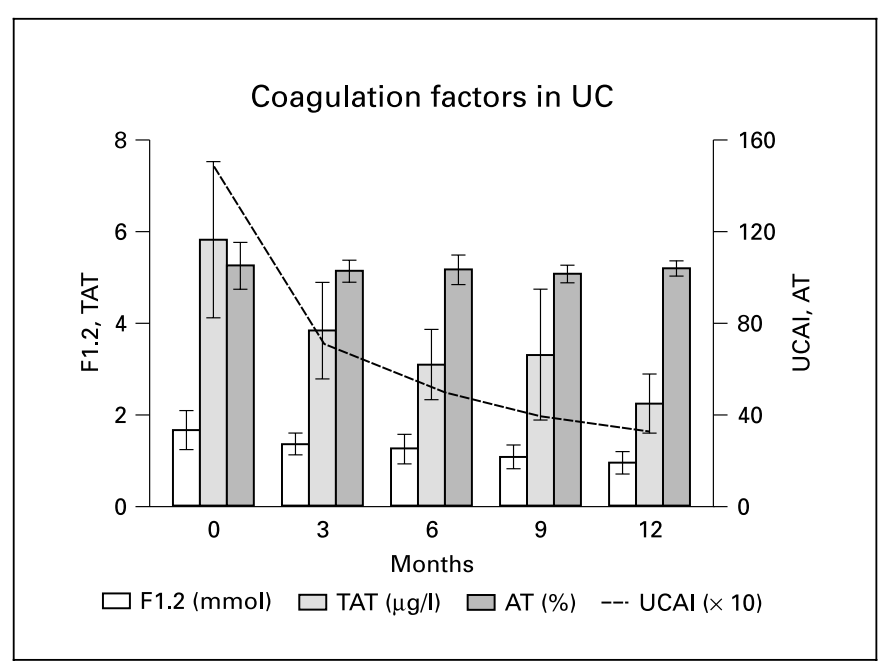

Fig. 3. Mean levels of F1.2, TAT and AT on entry and during 12 months of follow-up in 18 patients with UC. Sample sizes of F1.2, TAT and AT at 0, 3, 6, 9 and 12 months were 18, 16, 18, 17 and 17. The interrupted line shows the course of the UCAI. AT levels were in the normal range during 12 months of follow-up. Within 6 months, the mean TAT level was equal to the control group. However, even after 12 months of follow-up, the mean F1.2 levels were 1.5 times higher than the levels of the control group.

ease was still subclinically active. In theory, the medication could have promoted this disturbed pattern of hemostasis.

Corticosteroids can induce neutrophilia [41], and apart from fibrinolysis, high levels of D-dimer could result from neutrophilia in IBD and GCA, due to enhanced elastase release by these polymorph nuclear cells $[42,43]$. However, in CD and UC, the use of steroids resulted in a moderate decrease in D-dimer, F1.2 and PAP, and no significant difference in D-dimer was found between patients with or without steroid use. Corticosteroids might have reduced PAI-1 levels as in HenochSchönlein purpura [44], and in our study, levels of PAI-1 became low during follow-up. However, in IBD, steroids were generally withdrawn within 3-6 months, while mean PAI-1 levels did not change significantly between 3 and 12 months of follow-up.

To our knowledge, no direct effect of azathioprine on coagulation has been described. The use of azathioprine could have led to (opportunistic) infections, like e.g. cytomegalovirus reactivation, resulting in a disturbed coagulation [45]. However, no clinical signs of chronic (systemic) infections were encountered in our follow-up group. With oral 5ASA, a lower spontaneous ex vivo and

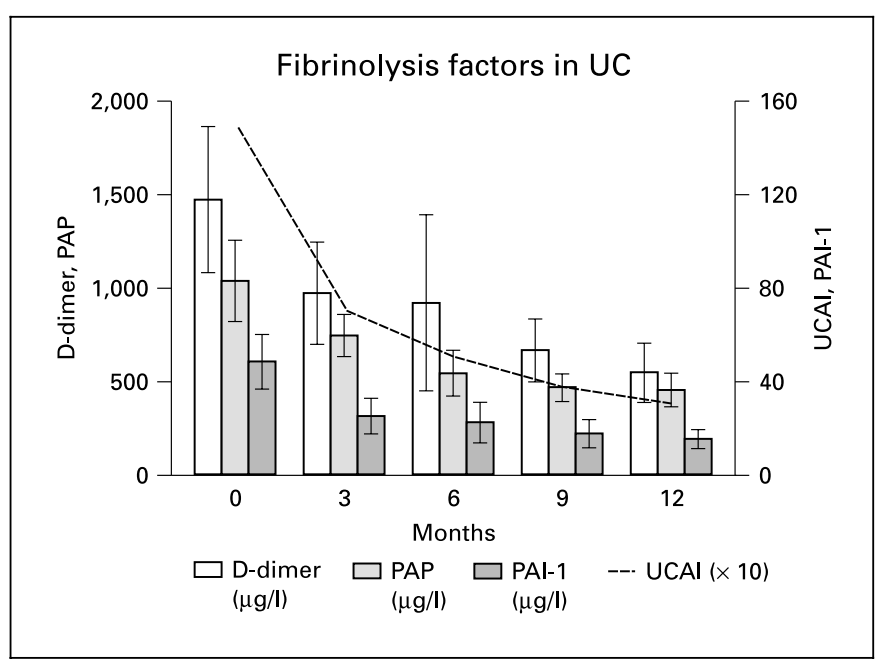

Fig. 4. Mean levels of D-dimer, PAP and PAI-1 on entry and during 12 months of follow-up in 18 patients with UC. Sample sizes of Ddimer, PAP and PAI-1 at 0, 3, 6, 9 and 12 months were 18, 16, 18, 17 and 17. The interrupted line shows the course of the UCAI. After 12 months of follow-up, the mean D-dimer and PAP levels were 2.0 and 1.6 times higher than the levels of the control group. However, PAI-1 levels were 1.7 times lower in UC as compared to the control group after 12 months of follow-up. in vitro platelet activation has been described in patients with IBD [46]. However, no secondary rise in coagulation and fibrinolysis factors has been documented.

It is unknown what exactly happens early in the course of IBD. Indirect evidence has come from recent studies that the activation of hemostasis and fibrinolysis is most likely a result of stimulation by certain cytokines from the inflammatory process in the gut, such as tumor necrosis factor- $\alpha$ [47]. Anti-tumor necrosis factor- $\alpha$ antibody $\left(\right.$ Remicade $\left.^{\circledR}\right)$ treatment was accompanied by a clear reduction in coagulation and fibrinolysis activity as studied in 8 patients with $\mathrm{CD}$ [48], suggesting a secondary role for the coagulation and fibrinolysis system in $\mathrm{CD}$.

Are the markers tested also clinically useful? A positive correlation was found between the CDAI as well as the UCAI with F1.2, TAT, D-dimer, PAP and PAI-1. Also, TAT, D-dimer, PAP and PAI-1 correlated with the extent of bowel involvement at entry. However, the persistently higher than normal levels of F1.2, D-dimer and PAP preclude their use as rapid diagnostics for measuring the influence of therapy, unlike e.g. an acute phase reactant like CRP [24, 49].

Nevertheless, the measurement of plasma concentrations of F1.2, TAT, D-dimer, PAP and PAI-1 could be 
useful as an additional tool. They might reflect inadequate control of the inflammatory process in the gut, and possibly a systemic tendency towards thromboembolic complications [50]. Future therapeutic intervention studies with drugs which could influence both inflammation and microvascular thrombosis [51] should therefore be welcomed.

\section{Acknowledgments}

The authors are indebted to Tramedico Incorporation for providing a fund thanks to which specific coagulation laboratory tests could be performed.

\section{References}

1 Brignola C, Lanfranchi GA, Campieri M, Bazzocchi G, Devoto M, Boni P, Farruggia P, Veggetti S, Tragnone A: Importance of laboratory parameters in the evaluation of Crohn's disease activity. J Clin Gastroenterol 1986;8/3:245248.

2 Ritchie DG, Levy BA, Adams MA: Regulation of fibrinogen synthesis by plasmin-derived fragments of fibrinogen and fibrin: An indirect feedback pathway. Proc Natl Acad Sci USA 1982;79:1530-1534.

3 Bauer KA, Rosenberg RD: The pathophysiology of the prethrombotic state in humans: Insights gained from studies using markers of hemostatic system activation. Blood 1987;70: 343-350.

4 Juhlin L, Kranse U, Shelley W: Endotoxininduced microclots in ulcerative colitis and Crohn's disease. Scand J Gastroenterol 1980; 15:311-314.

5 Wakefield AJ, Dhillon AP, Rowles PM, Sawyerr AM, Pittilo RM, Lewis AAM: Pathogenesis of Crohn's disease: Multifocal gastrointestinal infarction. Lancet 1989;ii:1057-1062.

6 Thornton M, Solomon MJ: Crohn's disease: In defense of a microvascular aetiology. Int $\mathrm{J}$ Colorectal Dis 2002;17/5:287-297.

7 Dhillon AP, Anthony A, Sim R, Wakefield AJ, Sankey EA, Hudson M, Allison MC, Pounder RE: Mucosal capillary thrombi in rectal biopsies. Histopathology 1992;21:127-133.

8 Talbot RW, Heppell J, Dozois RR, Beart RW: Vascular complications of inflammatory bowel disease. Mayo Clin Proc 1986;61:140-145.

9 Jackson LM, O'Gorman PJ, O'Connell J, Cronin CC, Cotter KP, Shanahan F: Thrombosis in inflammatory bowel disease: Clinical setting, procoagulant profile and factor V Leiden. QJM 1997;90/3:183-188.

10 Bernstein CN, Blanchard JF, Houston DS, Wajda A: The incidence of deep venous thrombosis and pulmonary embolism among patients with inflammatory bowel disease: A population-based cohort study. Thromb Haemost 2001;85:430-434.

11 Thompson N, Wakefield AJ, Pounder RE: Inherited disorders of coagulation appear to protect against inflammatory bowel disease. Gastroenterology 1995;108:1011-1015.

12 Liebman HA, Kashani N, Sutherland D, McGehee W, Kam AL: The factor V Leiden mutation increases the risk of venous thrombosis in patients with inflammatory bowel disease. Gastroenterology 1998;115:830-834.
13 Guedon C, Le Cam-Duchez V, Lalaude O, Menard JF, Lerebours E, Borg JY: Prothrombotic inherited abnormalities other than factor V Leiden mutation do not play a role in venous thrombosis in inflammatory bowel disease. Am J Gastroenterol 2001;96:1448-1454.

14 Bjerregaard LT, Nederby NJ, Fredholm L, Brandslund I, Munkholm P, Hey H: Hyperhomocysteinaemia, coagulation pathway activation and thrombophilia in patients with inflammatory bowel disease. Scand J Gastroenterol 2002;37/1:62-67.

15 Kader HA, Berman WF, Al-Seraihy AS, Ware RE, Ulshen MH, Treem WR: Prevalence of factor V G1691A (Leiden), prothrombin G20210A, and methylene tetrahydrofolate reductase C677T thrombophilic mutations in children with inflammatory bowel disease. $\mathrm{J}$ Pediatr Gastroenterol Nutr 2002;35:629-635.

16 Koutroubakis IE: Unraveling the mechanisms of thrombosis in inflammatory bowel disease. Am J Gastroenterol 2001;96:1325-1327.

17 Hudson M, Chitolie A, Hutton RA, Smith MSH, Pounder RE, Wakefield AJ: Thrombotic vascular risk factors in inflammatory bowel disease. Gut 1996;38:703-712.

18 Souto JC, Martinez E, Roca M, Mateo J, Pujol J, Gonzalez D, Fontcuberta J: Prothrombotic state and signs of endothelial lesion in plasma of patients with inflammatory bowel disease. Dig Dis Sci 1995;40:1883-1889.

19 Novacek G, Vogelsang H, Genser D, Moser G, Gangl A, Ehringer H, Koppensteiner R: Changes in blood rheology caused by Crohn's disease. Eur J Gastroenterol Hepatol 1996;8: 1089-1093.

20 de Jong E, Porte RJ, Knot EA, Verheijen JH, Dees J: Disturbed fibrinolysis in patients with inflammatory bowel disease. A study in blood plasma, colon mucosa, and faeces. Gut 1989; 30/2:188-194.

21 Seitz R, Leugner F, Katschinski M, Immel A, Kraus M, Egbring R, Goke B: Ulcerative colitis and Crohn's disease: Factor XIII, inflammation and haemostasis. Digestion 1994;55:361367.

22 Kjeldsen J, Lassen JF, Brandslund I, Schaffalitzky DE, Muckadell OB: Markers of coagulation and fibrinolysis as measures of disease activity in inflammatory bowel disease. Scand J Gastroenterol 1998;33:637-643.
23 van Bodegraven AA, Schoorl M, Baak JP, Linskens RK, Bartels PC, Tuynman HA: Hemostatic imbalance in active and quiescent ulcerative colitis. Am J Gastroenterol 2001;96: 487-493.

24 Linskens RK, van Bodegraven AA, Schoorl M, Tuynman HA, Bartels P: Predictive value of inflammatory and coagulation parameters in the course of severe ulcerative colitis. Dig Dis Sci 2001;46:644-648.

25 Hayat M, Ariens RA, Moayyedi P, Grant PJ, O'Mahony S: Coagulation factor XIII and markers of thrombin generation and fibrinolysis in patients with inflammatory bowel disease. Eur J Gastroenterol Hepatol 2002;14/3: 249-256.

26 Larsen TB, Nielsen JN, Fredholm L, Lund ED, Brandslund I, Munkholm P, Hey H: Platelets and anticoagulant capacity in patients with inflammatory bowel disease. Pathophysiol Haemost Thromb 2002;32/2:92-96.

27 Hunder G, Bloch DA, Michel BA, Steven MB, Arend WP, Calbrese LH, Edworthy SM, Fauci AS, Leavitt RY, Lie JT, Lightfoot RW Jr, Masi AT, Mcshane DJ, Mills JA, Wallace SL, Zvaifler HJ: The American College of Rheumatology 1990 criteria for the classification of giant cell arteritis. Arthritis Rheum 1990;33:11221128.

28 Lennard-Jones GE: Classification of inflammatory bowel disease. Scand J Gastroenterol 1989;24(suppl 170:)2-6.

29 Best WR, Becktel JM, Singleton JW, Kern F: Development of a Crohn's disease activity index. Gastroenterology 1976;70:439-444.

30 Truelove-Witts SS, Witts LJ: Cortisone in ulcerative colitis: Final report on a therapeutic trial. BMJ 1955; ii:1042-1048.

31 Vrij AA, Rijken J, van Wersch JWJ, Stockbrügger RW: Platelet factor 4 and $\beta$-thrombo-globulin in inflammatory bowel disease and giant cell arteritis. Eur J Clin Invest 2000;30:188194.

32 Hazleman BL, Bengtsson B-Å: Giant cell arteritis and polymyalgia rheumatica; in Hazleman BL, Bengtsson B-A (eds): Clinical Rheumatology. London, Baillière, Tindall, 1991, vol 5, No 3, pp 371-378.

33 Tofler GH, Brezinski D, Schafer AI, Czeisler CA, Rutherford JD, Willich SN, Gleason RE, Williams GH, Muller JE: Concurrent morning increase in platelet aggregability and the risk of myocardial infarction and sudden cardiac death. N Engl J Med 1987;316:1514-1518. 
34 Vrij AA, Jansen JM, Schoon EJ, de Bruïne A, Hemker HC, Stockbrügger RW: Low molecular weight heparin treatment in steroid refractory ulcerative colitis: Clinical outcome and influence on mucosal capillary thrombi. Scand J Gastroenterol 2001;36(suppl 234):41-47.

35 Heneghan MA, Cleary B, Murray M, O'Gorman TA, McCarthy CF: Activated protein C resistance, thrombophilia, and inflammatory bowel disease. Dig Dis Sci 1998;43:13561361.

36 van Bodegraven AA, Schoorl M, Linskens RK Bartels PC, Tuynman HA: Persistent activation of coagulation and fibrinolysis after treatment of active ulcerative colitis. Eur J Gastroenterol Hepatol 2002;14:413-418.

37 Taylor FB Jr, Toh C-H, Hoots WK, Wada H, Levi M; Scientific Subcommittee on Disseminated Intravascular Coagulation (DIC) of the International Society on Thrombosis and Haemostasis (ISTH): Towards definition, clinical and laboratory criteria, and a scoring system for disseminated intravascular coagulation. Thromb Haemost 2001;86:1327-1330.

38 ver Elst K, Jochmans K, de Pauw A, de Waele $\mathrm{M}$ : Plasma D-dimer concentrations in different clinical conditions. Acta Clin Belg 2002;57: 325-330.

39 Van der Bom JG, Bots ML, Haverkate F, Meijer P, Hofman A, Kluft C, Grobbee DE: Activation products of the haemostatic system in coronary, cerebrovascular and peripheral arteria disease. Thromb Haemost 2001;85/2:234 239.
40 Cohen HJ, Harris T, Pieper CF: Coagulation and activation of inflammatory pathways in the development of functional decline and mortality in the elderly. Am J Med 2003;114/3: 180-187.

41 Stadnicki A, Gonciarz M, Niewiarowski TJ, Hartleb J, Rudnicki M, Merrell NB, De la Cadena RA, Colman RW: Activation of plasma contact and coagulation systems and neutrophils in the active phase of ulcerative colitis. Dig Dis Sci 1997;42:2356-2366.

42 De la Cadena RA, Wachtfogel YT, Colman RW: Contact activation pathway: Inflammation and coagulation; in Colman RW, Hirsh J, Marder VJ, Salzman EW (eds): Hemostasis and Thrombosis: Basic Principles and Clinical Practice. Philadelphia, Lippincott, 1994, p 219.

43 Sampson AP: The role of eosinophils and neutrophils in inflammation. Clin Exp Allergy 2000;30(suppl 1):22-27.

44 Prandota J, Pankow-Prandota L, Kotecki L: Impaired activation of the fibrinolytic system in children with Henoch-Schonlein purpura: Beneficial effect of hydrocortisone plus Sigmaaminocaproic acid therapy on disappearance rate of cutaneous vasculitis and fibrinolysis. Am J Ther 2001;8/1:11-19.

45 Bouwman JJ, Visseren FL, Bosch MC, Bouter KP, Diepersloot RJ: Procoagulant and inflammatory response of virus-infected monocytes. Eur J Clin Invest 2002;32:759-766.
46 Carty E, MacEy M, Rampton DS: Inhibition of platelet activation by 5-aminosalicylic acid in inflammatory bowel disease. Aliment Pharmacol Ther 2000;14/9:1169-1179.

47 Lilja I, Gustafson-Svard C, Franzen L, Sjodahl $\mathrm{R}$ : Tumor necrosis factor- $\alpha$ in ileal mast cells in patients with Crohn's disease. Digestion 2000; 61/1:68-76.

48 Hommes DW, van Dullemen HM, Levi M, van der Ende A, Woody J, Tytgat GN, van Deventer SJ: Beneficial effect of treatment with a monoclonal anti-tumor necrosis factor- $\alpha$ antibody on markers of coagulation and fibrinolysis in patients with active Crohn's disease. Haemostasis 1998;27/6:269-277.

49 Poullis AP, Zar S, Sundaram KK, Moodie SJ Risley P, Theodossi A, Mendall MA: A new, highly sensitive assay for C-reactive protein can aid the differentiation of inflammatory bowel disorders from constipation- and diarrhoea-predominant functional bowel disorders Eur J Gastroenterol Hepatol 2002;14:409_ 412.

50 Novacek G, Miehsler W, Kapiotis S, Katzenschlager R, Speiser W, Vogelsang $\mathrm{H}$ : Thrombo-embolism and resistance to activated protein $\mathrm{C}$ in patients with inflammatory bowel disease. Am J Gastroenterol. 1999;94:685690.

51 Tyrrell DJ, Horne AP, Holme KR, Preuss JM, Page CP: Heparin in inflammation: Potential therapeutic applications beyond anticoagulation. Adv Pharmacol 1999;46:151-208. 